\title{
Transient Monitoring Function based Fault Classifier for Relaying Applications
}

\author{
P. R. Pattanaik, S. Pati, S. K. Sanyal \\ Department of Electrical Engineering, Siksha 'O' Anusandhan Deemed University, India
}

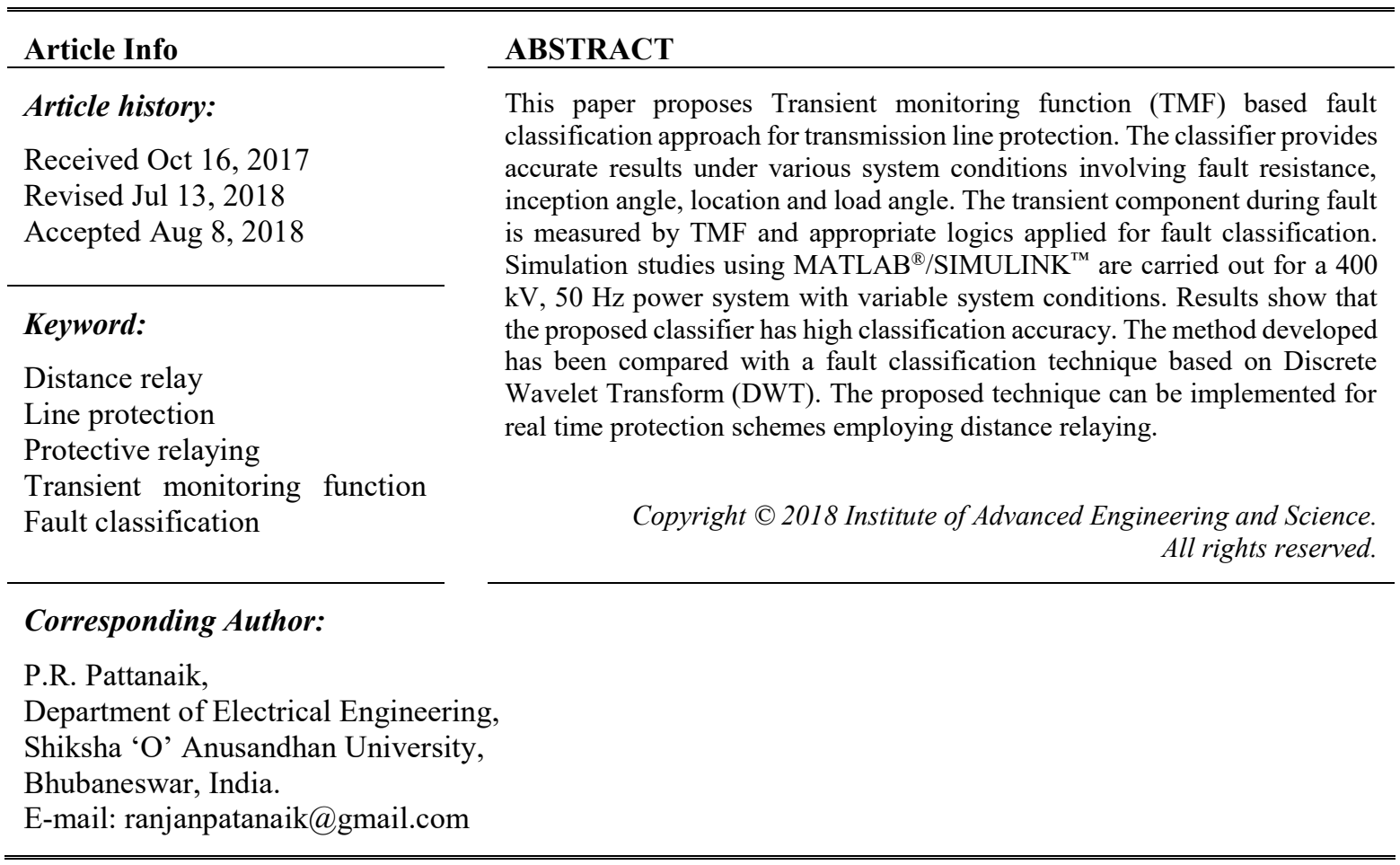

\section{INTRODUCTION}

Distance relay connected to a transmission line is required to operate for all types of fault within the protected zone. It is essential to determine correct type of fault in case of digital relaying for transmission line protection. The trip boundary is set according to the fault type as impedance seen by distance relay is not same for all types of fault [1]. Fault classification and location in a transmission line have been determined using modular artificial neural networks (ANNs) [2]. Optimal probabilistic neural network (PNN) with particle swarm optimization technique (PSO) has been considered for fault classification in a high voltage line [3]. PNN based method using Discrete wavelet transforms (DWT) are applied for classifying faults wherein DWT acts as an extractor of distinctive feature of input current signal [4]-[6]. Protection techniques based on different types of ANNs such as generalized neural networks, unsupervised/supervised neural networks, online trained neural networks and radial function basis neural networks are presented in [7]-[11]. Principle component analysis (PCA) based techniques have been applied to identify and classify faults in three phase transmission lines [12].

Literature shows neuro-fuzzy based techniques are widely considered for fault classification in modern power system involving complex networks [13]. ANN trained network can only be used in a system for which it is trained and implementing the same ANN to other network becomes cumbersome. An 8-bit microprocessor based technique for real time implementation is proposed in [14]. In this method voltage phasors are obtained using Kalman filtering and processed through a MC6809B microcontroller to distinguish between various classes of faults. The identification and classification of faults in HVDC system using wavelet analysis has been proposed in [15]. A deterministic fault classification method had been proposed in [16]. Linear perceptron based algorithm has been suggested to distinguish between grounded and ungrounded faults 
for a distribution system [17]. The TMF has been used to differentiate between fault and a power swing to prevent maloperation of distance relay in zone-3 [18], [19].

This paper proposes a TMF based fault classifier wherein transient monitor (TM) indices of three phases are computed. The faulted phase TM index will exceed the threshold value and fault type can be identified through proposed logics. The phasor extraction of fundamental component of current signal is used to obtain the reconstructed signal. The phasor extraction accuracy of one-cycle DFT being high results in reduction of threshold value. The proposed method has been compared with wavelet transform based technique [16]. A $400 \mathrm{kV}$ system has been simulated for different types of faults considering several factors.

\section{FAULT CLASSIFICATION TECHNIQUES}

\subsection{Fault Classification Using DWT}

Discrete wavelet transform (DWT) can effectively analyse transient current and voltage. DWT analyse signals in different frequency band using short window for high frequency and long window for low frequency [20]. Therefore signal can be analysed in both time and frequency domain. Wavelet decomposes the signal in different frequency bands obtained from mother wavelet by dilation and translation. The wavelet transform of signal $f(t)$ can be represented by following equation as:

$$
W T(f, p, q)=\frac{1}{\sqrt{p}} \int_{-\infty}^{+\infty} f(t) w\left(\frac{t-q}{p}\right)
$$

where ' $p$ ', ' $q$ ' and ' $w$ ' are scaling constant, translation constant and wavelet function respectively. Discrete wavelet transform can be applied to transform of sampled waveforms as:

$$
D W T(f, h, j)=\frac{1}{\sqrt{p_{0}^{h}}} \sum_{k} f(t) w\left(\frac{n-k p_{0}^{h}}{p_{0}^{h}}\right)
$$

where ' $p_{0}{ }^{h}$ ' and ' $k p_{0}{ }^{h}$ ' are scaling constant and translation constant respectively.

The DWT can be implemented with successive pairs of high pass and low pass filters at each scaling stage. This is equivalent to successive approximation of same function where each approximation gives the incremental information referred to a particular scale. The shorter scale involves high frequency range and longer scale refers to low frequency of the spectrum. DWT decomposes a signal into a set of approximate and detailed coefficients. The wavelet transform based fault classification analysis involves mean of the approximate coefficients obtained from the DWT of each phase current at scale 1 and absolute value of the means are termed as $\mathrm{M}_{\mathrm{a}}, \mathrm{M}_{\mathrm{b}}$ and $\mathrm{M}_{\mathrm{c}}$ respectively. Determination of fault type is carried out with logics shown in Table 1.

Table 1. Fault Classification logics for DWT Technique

\begin{tabular}{cc}
\hline Fault Type & Fault Classification Logics \\
\hline A-G & $M_{a}>M_{b} \& M_{a}>M_{c} \& M_{b}=M_{c}$ \\
B-G & $M_{b}>M_{a} \& M_{b}>M_{c} \& M_{a}=M_{c}$ \\
C-G & $M_{c}>M_{a} \& M_{c}>M_{b} \& M_{a}=M_{b}$ \\
A-B-G & $M_{a}>M_{c} \& M_{b}>M_{c} \& M_{a}+M_{b} \geq 2 M_{c}$ \\
B-C-G & $M_{b}>M_{a} \& M_{c}>M_{a} \& M_{b}+M_{c} \geq 2 M_{a}$ \\
C-A-G & $M_{a}>M_{b} \& M_{c}>M_{a} \& M_{a}+M_{c} \geq 2 M_{b}$ \\
A-B & $M_{a}>M_{c} \& M_{b}>M_{c} \& M_{a}=M_{c}$ \\
B-C & $M_{b}>M_{a} \& M_{c}>M_{a} \& M_{b}=M_{c}$ \\
C-A & $M_{b}>M_{a} \& M_{a}>M_{b} \& M_{a}=M_{c}$ \\
A-B-C & $\left(M_{a} \neq M_{b} \neq M_{c}\right) \&\left(M_{a}+M_{b}=M_{c}\right) \&\left(M_{b}+M_{c}=M_{a}\right) \&\left(M_{a}+M_{c}=M_{b}\right)$ \\
\hline
\end{tabular}

\subsection{Transient Monitoring Function}

The fundamental component of current signal can be extracted by using a phasor estimation technique [1]. One cycle DFT has been considered for phasor estimation in order to reconstruct a signal from its phasor value at a given instant. In normal condition there will be no difference between the actual current signal and the reconstructed one. However any type of fault initiation results in significant difference between the two signals due to presence of transient component in fault signal. The absolute sum of squared difference between the actual signal and reconstructed signal over one cycle window length termed as TMF. Transient monitoring 
had been applied to determine the accuracy of phasor estimation [20]. In this paper TMF is used as a fault classifier. The mathematical formulation of the TMF using Fourier transform approach has been outlined as follows.

In the present paper fundamental frequency phasor value at each instant can be calculated using one cycle DFT. A data window of one cycle continuously moves forward and adds one sample corresponds to that instant. The phasor calculation for transient period will provide value for $50 \mathrm{~Hz}$ only. The current signal is reconstructed with phasor values obtained and compared with actual current signal. It can be observed from Figure 1 that during transient period two signals mismatches and TMF value increases. A sinusoidal current signal can be expressed as

$$
i_{k}=I_{m} \cos (\alpha \kappa+\varphi)
$$

where $I_{m}$ is the amplitude of current signal, $\mathrm{k}$ is the sample number, $\varphi$ is the phase angle in radians and $\alpha=2 \pi / \mathrm{N}$ ( $\mathrm{N}$ is one cycle window length). DFT of the sinusoidal current signal corresponding to fundamental frequency is

$$
I_{1}=\frac{2}{N} \sum_{k=0}^{N-1} i_{k} e^{-j \frac{2 \Pi}{N} k}
$$

where $I_{1}$ is the phasor estimated in terms of peak and can also be represented as

$$
I_{1}=I_{m} e^{j \varphi}
$$

The signal can be reconstructed by using phasor values at each instant as

$$
\hat{i}_{k}=\left[I_{m} e^{j \varphi}\right] e^{j \omega_{0} k T s}
$$

where $T_{\mathrm{s}}$ is the sampling time and $\omega_{0}$ is the fundamental angular frequency. According to the definition of the $\mathrm{TMF}$, it can be expressed as

$$
T M F=\sum_{k=1}^{N} C_{k}
$$

where

$$
C_{k}=\left(i_{k}-\hat{i}_{k}\right)^{2}
$$

At the inception of any type of fault, large transients will be observed in fault signal and TMF will maintain high index for few cycles. It can be observed from Figure 1 that actual current signal exactly matches with reconstructed current signal before fault initiation (at $0.5 \mathrm{~s}$ ). There occurs a mismatch during transient period although TMF maintains zero index value before fault and changing significantly during transient period. Fault classification is carried out using post fault current data of the three phases at one end of the line. Using these data TM indices for the three phases and ground are calculated and termed as $\mathrm{TM}_{\mathrm{a}}, \mathrm{TM}_{\mathrm{b}}, \mathrm{TM}_{\mathrm{c}}$, and $\mathrm{TM}_{\mathrm{g}}$ where suffices $\mathrm{a}, \mathrm{b}, \mathrm{c}$ and $\mathrm{g}$ relate to phase $\mathrm{A}$, phase $\mathrm{B}$, phase $\mathrm{C}$ and ground respectively.

$$
\begin{aligned}
& T M_{a}=T M F_{a}\left(\frac{F I T}{T_{S}}+N\right) \\
& T M_{b}=T M F_{b}\left(\frac{F I T}{T_{S}}+N\right) \\
& T M_{c}=T M F_{c}\left(\frac{F I T}{T_{S}}+N\right)
\end{aligned}
$$




$$
T M_{g}=T M F_{g}\left(\frac{F I T}{T_{S}}+N\right)
$$

Where, FIT is the fault inception time. A delay of one cycle is considered for higher value of TM index. The total time taken for fault classification lies between one cycle and two cycles. The proposed fault classification technique requires accurate fault detection as a prerequisite. The logics for determining different types of faults are developed in terms of TM indices as illustrated in Table 2.

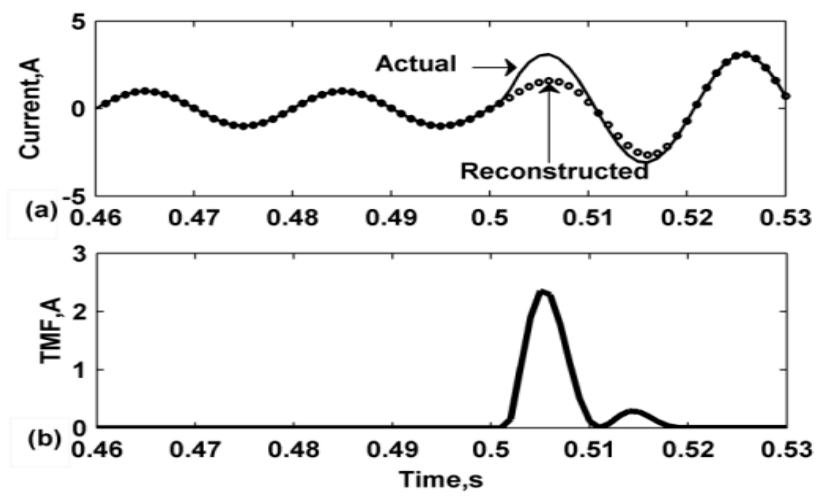

Figure 1. (a) Comparison between actual and reconstructed signal. (b) Transient monitor

Table 2. Fault Classification logics for TMF method

\begin{tabular}{cc}
\hline Fault Type & Fault Classification Logics \\
\hline A-G & $\mathrm{TM}_{\mathrm{a}} \geq \mathrm{h}_{\mathrm{p}} \& \mathrm{TM}_{\mathrm{b}}<\mathrm{h}_{\mathrm{p}} \& \mathrm{TM}_{\mathrm{c}}<\mathrm{h}_{\mathrm{p}} \& \mathrm{TM}_{\mathrm{g}} \geq \mathrm{h}_{\mathrm{g}}$ \\
B-G & $\mathrm{TM}_{\mathrm{a}}<\mathrm{h}_{\mathrm{p}} \& \mathrm{TM}_{\mathrm{b}} \geq \mathrm{h}_{\mathrm{p}} \& \mathrm{TM}_{\mathrm{c}}<\mathrm{h}_{\mathrm{p}} \& \mathrm{TM}_{\mathrm{g}} \geq \mathrm{h}_{\mathrm{g}}$ \\
C-G & $\mathrm{TM}_{\mathrm{a}}<\mathrm{h}_{\mathrm{p}} \& \mathrm{TM}_{\mathrm{b}}<\mathrm{h}_{\mathrm{p}} \& \mathrm{TM}_{\mathrm{c}} \geq \mathrm{h}_{\mathrm{p}} \& \mathrm{TM}_{\mathrm{g}} \geq \mathrm{h}_{\mathrm{g}}$ \\
A-B-G & $\mathrm{TM}_{\mathrm{a}} \geq \mathrm{h}_{\mathrm{p}} \& \mathrm{TM}_{\mathrm{b}} \geq \mathrm{h}_{\mathrm{p}} \& \mathrm{TM}_{\mathrm{c}}<\mathrm{h}_{\mathrm{p}} \& \mathrm{TM}_{\mathrm{g}} \geq \mathrm{h}_{\mathrm{g}}$ \\
B-C-G & $\mathrm{TM}_{\mathrm{a}}<\mathrm{h}_{\mathrm{p}} \& \mathrm{TM}_{\mathrm{b}} \geq \mathrm{h}_{\mathrm{p}} \& \mathrm{TM}_{\mathrm{c}} \geq \mathrm{h}_{\mathrm{p}} \& \mathrm{TM}_{\mathrm{g}} \geq \mathrm{h}_{\mathrm{g}}$ \\
C-A-G & $\mathrm{TM}_{\mathrm{a}} \geq \mathrm{h}_{\mathrm{p}} \& \mathrm{TM}_{\mathrm{b}}<\mathrm{h}_{\mathrm{p}} \& \mathrm{TM}_{\mathrm{c}} \geq \mathrm{h}_{\mathrm{p}} \& \mathrm{TM}_{\mathrm{g}} \geq \mathrm{h}_{\mathrm{g}}$ \\
A-B & $\mathrm{TM}_{\mathrm{a}} \geq \mathrm{h}_{\mathrm{p}} \& \mathrm{TM}_{\mathrm{b}} \geq \mathrm{h}_{\mathrm{p}} \& \mathrm{TM}_{\mathrm{c}}<\mathrm{h}_{\mathrm{p}} \& \mathrm{TM}_{\mathrm{g}}<\mathrm{h}_{\mathrm{g}}$ \\
B-C & $\mathrm{TM}_{\mathrm{a}}<\mathrm{h}_{\mathrm{p}} \& \mathrm{TM}_{\mathrm{b}} \geq \mathrm{h}_{\mathrm{p}} \& \mathrm{TM}_{\mathrm{c}} \geq \mathrm{h}_{\mathrm{p}} \& \mathrm{TM}_{\mathrm{g}}<\mathrm{h}_{\mathrm{g}}$ \\
C-A & $\mathrm{TM}_{\mathrm{a}} \geq \mathrm{h}_{\mathrm{p}} \& \mathrm{TM}_{\mathrm{b}}<\mathrm{h}_{\mathrm{p}} \& \mathrm{TM}_{\mathrm{c}} \geq \mathrm{h}_{\mathrm{p}} \& \mathrm{TM}_{\mathrm{g}}<\mathrm{h}_{\mathrm{g}}$ \\
A-B-C & $\mathrm{TM}_{\mathrm{a}} \geq \mathrm{h}_{\mathrm{p}} \& \mathrm{TM}_{\mathrm{b}} \geq \mathrm{h}_{\mathrm{p}} \& \mathrm{TM}_{\mathrm{c}} \geq \mathrm{h}_{\mathrm{p}} \& \mathrm{TM}_{\mathrm{g}}<\mathrm{h}_{\mathrm{g}}$
\end{tabular}

' $h_{p}$ ' and ' $h_{g}$ ' are the thresholds for phase and ground indexes respectively.

\section{RESULTS AND DISCUSSION}

A two terminal, $400 \mathrm{kV}, 3$ phases, $128 \mathrm{Km}$ transmission line model has been considered as shown in Figure 2. The proposed classification method has been compared with DWT technique to show effectiveness and accuracy of TMF based classifier. All parameters related to the transmission line model are given in Appendix I.

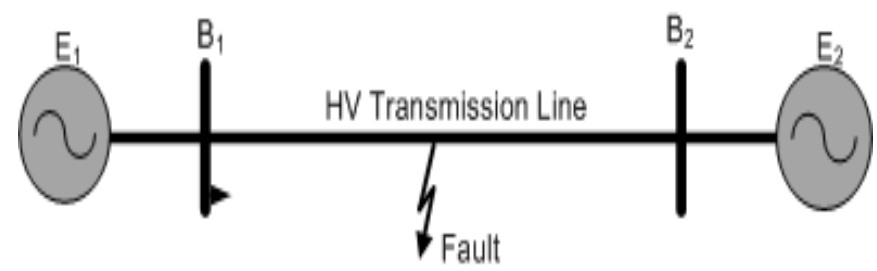

Figure 2. Transmission Line model

Extensive simulation studies using $\mathrm{MATLAB}^{\circledR} / \mathrm{SIMULINK}^{\mathrm{TM}}$ have been carried out for variations in the values of fault resistance $\left(R_{F}\right)$, fault inception angle (FIA), fault location $(d)$ and load angle $(\delta)$. Normalized phase currents are processed and classification indices of DWT and TMF for phase and ground are obtained 
for different types of fault under various system conditions. The indices value obtained for DWT and TMF method are given in Table 3 and Table 4 respectively. It is found from Table 3 that in few instances DWT indices fail to satisfy their corresponding logics with respect to fault type under particular system condition. Table 4 shows TMF indices satisfy their corresponding logics under the same system condition.

Table 3. Values of DWT indices for various operating conditions

\begin{tabular}{cccccc}
\hline Fault Type & $\begin{array}{c}\text { Fault Condition: } \\
\mathrm{d}, \mathrm{R}_{\mathrm{F}}, \text { FIA, } \delta\end{array}$ & $\left|\mathrm{M}_{\mathrm{a}}\right|$ & $\left|\mathrm{M}_{\mathrm{b}}\right|$ & $\left|\mathrm{M}_{\mathrm{c}}\right|$ & $\left|\mathrm{M}_{\mathrm{g}}\right|$ \\
\hline \multirow{3}{*}{$\mathrm{A}-\mathrm{G}$} & $0.5,50 \Omega, 20^{\circ}, 20^{\circ}$ & 0.0024 & 0.0100 & 0.0069 & 0.0020 \\
& $0.1,00 \Omega, 45^{\circ}, 20^{\circ}$ & 0.2353 & 0.0104 & 0.0273 & 0.0910 \\
& $0.9,10 \Omega, 25^{\circ}, 10^{\circ}$ & 0.0132 & 0.0121 & 0.0042 & 0.0018 \\
\multirow{2}{*}{ B-C-G } & $0.5,50 \Omega, 20^{\circ}, 20^{\circ}$ & 0.002 & 4.334 & 6.691 & 0.571 \\
& $0.1,05 \Omega, 60^{\circ}, 30^{\circ}$ & 0.071 & 76.73 & 121.1 & 3.848 \\
& $0.9,100 \Omega, 90^{\circ}, 10^{\circ}$ & 0.006 & 1.470 & 1.600 & 0.113 \\
\multirow{2}{*}{ B-C } & $0.5,10 \Omega, 20^{\circ}, 30^{\circ}$ & 0.000 & 13.53 & 13.24 & 0.000 \\
& $0.1,02 \Omega, 85^{\circ}, 15^{\circ}$ & 0.000 & 727.3 & 731.8 & 0.000 \\
\hline
\end{tabular}

Table 4. Values of TM indices for various operating conditions

\begin{tabular}{cccccc}
\hline Fault Type & $\begin{array}{c}\text { Fault Condition: } \\
\mathrm{d}, \mathrm{R}_{\mathrm{F}}, \mathrm{FIA}, \delta\end{array}$ & $\mathrm{TM}_{\mathrm{a}}$ & $\mathrm{TM}_{\mathrm{b}}$ & $\mathrm{TM}_{\mathrm{c}}$ & $\mathrm{TM}_{\mathrm{g}}$ \\
\hline \multirow{3}{*}{$\mathrm{A}-\mathrm{G}$} & $0.5,50 \Omega, 20^{\circ}, 20^{\circ}$ & 5.457 & 0.002 & 0.002 & 0.600 \\
& $0.1,00 \Omega, 45^{\circ}, 20^{\circ}$ & 258.7 & 0.731 & 0.729 & 35.12 \\
& $0.9,10 \Omega, 25^{\circ}, 10^{\circ}$ & 49.68 & 0.267 & 0.267 & 4.028 \\
B-C-G & $0.5,50 \Omega, 20^{\circ}, 20^{\circ}$ & 0.002 & 4.334 & 6.691 & 0.571 \\
& $0.1,05 \Omega, 60^{\circ}, 30^{\circ}$ & 0.071 & 76.73 & 121.1 & 3.848 \\
& $0.9,100 \Omega, 90^{\circ}, 10^{\circ}$ & 0.006 & 1.470 & 1.600 & 0.113 \\
B-C & $0.5,10 \Omega, 20^{\circ}, 30^{\circ}$ & 0.000 & 13.53 & 13.24 & 0.000 \\
& $0.1,02 \Omega, 85^{\circ}, 15^{\circ}$ & 0.000 & 727.3 & 731.8 & 0.000 \\
& $0.9,50 \Omega, 50^{\circ}, 20^{\circ}$ & 0.000 & 1.152 & 1.148 & 0.000 \\
\hline
\end{tabular}

In literature different types of fault classification logics are found based on their fault classifier indices. The classifier index for three phases has been compared with each other. Alternatively the indices may be compared with a pre specified threshold value. In DWT technique $|\mathrm{M}|$ indices are compared with each other leading to inaccurate results due to a small margin between phase indices. It can be observed from Tables 1 and 3 that logics based on comparison of phase indices results in false identification of fault type. TM indices are compared with a threshold value resulting in accurate identification of fault type. The value of thresholds ' $h_{\mathrm{p}}$ ' and ' $\mathrm{h}_{\mathrm{g}}$ ' are taken as 1 and 0.01 respectively. Optimal threshold is necessary to obtain accurate fault classification. Values of $\mathrm{TM}_{\mathrm{a}}$ and $\mathrm{TM}_{\mathrm{g}}$ for $\mathrm{A}-\mathrm{G}$ fault are greater than $\mathrm{h}_{\mathrm{p}}$ and $\mathrm{h}_{\mathrm{g}}$ respectively whereas values of $\mathrm{TM}_{\mathrm{b}}$ and $\mathrm{TM}_{\mathrm{c}}$ smaller than $\mathrm{h}_{\mathrm{p}}$. The results obtained shown in Table 4 validates the logics of Table 2 for other types of faults.

Threshold value may depend upon constraints such as noise, harmonics, frequency variation and sampling rate. Phasor estimation quality affects the threshold value since phasor estimation accuracy decides similarity between actual and reconstructed signals. The difference between these two signals under prefault condition remains low leading to a very high value during fault conditions. One cycle delay after FIT is considered for high value of TM index as high threshold value avoids inaccurate classification.

In the proposed method probability of correctness $\left(P_{c}\right)$ is obtained for different cases to validate high classification accuracy. The parameter variation in each case over a long range has been studied in order to calculate $P_{c}$. The sample space in each case consists of total number of parameter variation and favorable events pertaining to total number of correct classification. Mathematically ' $P_{c}$ ' can be expressed as:

$$
P_{C}=\frac{\text { Number of correct classification }}{\text { Number of iteration steps in each case }} \times 100
$$

The results using TMF shown in Table 5 reveal that the proposed method has high accuracy for wide range of operating conditions. The computation has been made for variation in $\mathrm{R}_{\mathrm{F}}$ up to $130 \Omega, \mathrm{d}$ and $\delta$ up to 0.95 (p.u) line length and $50^{\circ}$ respectively. The transmission line resistance upto the fault point and fault resistance influence performance of proposed classifier. The low resistance results in high transient leading to increased mutual inductance between phases. High mutual inductance generate transient in healthy phases. TM indices of healthy phases increase due to presence of transients. The problem of high mutual inductance effect may be eliminated with the design of appropriate filters. It is found that proposed classifier is not affected due 
variation in fault inception angle and load angle. The proposed technique is simple and straightforward as it requires a DFT based filtering algorithm and difference between two signals.

Table 5. Classification accuracy of TMF method

\begin{tabular}{ccccc}
\hline Fault Type & Fixed Conditions & Variable parameter & Step Size & $\mathrm{P}_{\mathrm{c}}$ \\
\hline A-G & $\mathrm{d}=0.5, \mathrm{FIA}=45^{\circ}, \delta=20^{\circ}$ & $\mathrm{R}_{\mathrm{F}}=0 \Omega$ to $135 \Omega$ & $1 \Omega$ & $96.30 \%$ \\
B-C-G & $\mathrm{FIA}=10^{\circ}, \delta=10^{\circ}, \mathrm{R}_{\mathrm{F}}=50 \Omega$ & $\mathrm{d}=0.01$ to 0.95 & $0.01(\mathrm{p} . \mathrm{u})$ & $98.90 \%$ \\
A-C & $\delta=10^{\circ}, \mathrm{R}_{\mathrm{F}}=100 \Omega, \mathrm{d}=0.5$ & $\mathrm{FIA}=0^{\circ}$ to $360^{\circ}$ & $1^{\circ}$ & $100.00 \%$ \\
A-C-G & $\mathrm{R}_{\mathrm{F}}=100 \Omega, \mathrm{d}=0.5, \mathrm{FIA}=30^{\circ}$ & $\delta=5^{\circ}$ to $50^{\circ}$ & $1^{\circ}$ & 100.0 \\
\hline
\end{tabular}

\section{CONCLUSION}

A simple method for fault classification of power system has been proposed. The method employs a transient monitoring function based technique using current signals at one end of the line. Requisite logics with threshold values have been found to classify different type of fault. Simulation studies for various type of fault have been carried out. The effects of fault location, fault inception angle, fault resistance and load angle have been considered. It has been found that results obtained using proposed method are highly accurate compared to the Discrete Wavelet transform based method.

\section{ACKNOWLEDMENTS}

The authors acknowledge help and support provided by S'O’A Demmed University, Bhubaneswar.

\section{APPENDIX I}

The system information is given for power system operating at $50 \mathrm{~Hz}$. For all instance negative sequence impedance is equal to positive sequence impedance.

I. Source voltages:

- Source 1: $\mathrm{E}_{1}=400 \mathrm{kV}$

- Source 2: $\mathrm{E}_{2}=400 \angle \delta \mathrm{kV}$, where $\delta$ is the power angle.

II. Source impedance: (Source 1)

- $\quad$ Positive sequence impedance $=1.74+\mathrm{j} 19.92 \Omega$

- Zero sequence impedance $=2.6100+\mathrm{j} 29.8858 \Omega$

III. Source impedance: (Source 2)

- Positive sequence impedance $=0.87+\mathrm{j} 9.96 \Omega$

- Zero sequence impedance $=1.3050+\mathrm{j} 14.9400 \Omega$

IV. Transmission line parameters (per km).

- Positive sequence impedance $=0.0256+\mathrm{j} 0.3670 \Omega$

- Zero sequence impedance $=0.1362+\mathrm{j} 1.1096 \Omega$

V. Sampling Time: 1 millisecond.

VI. Line Length: $128 \mathrm{~km}$.

\section{REFERENCES}

[1] Anderson P. M., "Power system protection," Wiley, 1998.

[2] Hagh M. T., et al., "Fault classification and location of power transmission lines using artificial neural network," Power Engineering Conference, 2007. IPEC 2007, pp. 1109-1114, 2007.

[3] Khodaparastan M., et al., "Smart fault classification in HVDC system based on optimal probabilistic neural networks," Smart Grids (ICSG), 2012 2nd Iranian Conference, pp. 1-4, 2012.

[4] Upendar J., et al., "Discrete wavelet transform and probabilistic neural network based algorithm for classification of fault on transmission systems," India Conference, INDICON 2008. Annual IEEE, vol. 1, pp. 206-211, 2008.

[5] Youssef O. A., "Fault classification based on wavelet transforms," Transmission and Distribution Conference and Exposition, 2001 IEEE/PES, vol. 1, pp. 531-536, 2001.

[6] P. Sharma, et al., "Fault Detection and Classification in Transmission Line Using Wavelet Transform and ANN," Bulletin of Electrical Engineering and Informatics, vol/issue: 5(4), pp. 456-465, 2016.

[7] Song Y. H., et al., "Artificial neural-network-based protection scheme for controllable series-compensated EHV transmission lines," IEE Proceedings-generation, transmission and distribution, vol/issue: 143(6), 1996.

[8] Aggarwal R. K., et al., "A novel fault classification technique for double-circuit lines based on a combined unsupervised/supervised neural network," IEEE transactions on Power Delivery, vol/issue: 14(4), 1999. 
[9] Osman A. H., et al., "Transmission line distance relaying using on-line trained neural networks," IEEE Transactions on power delivery, vol/issue: 20(2), pp. 1257-64, 2005.

[10] Dash P. K., et al., "Application of minimal radial basis function neural network to distance protection," IEEE Transactions on Power Delivery, vol/issue: 16(1), pp. 68-74, 2001.

[11] Mahanty R. N. and Dutta G. P. B., "Comparison of fault classification methods based on wavelet analysis and ANN," Electric Power Components and Systems, vol/issue: 34(1), pp. 47-60, 2006.

[12] Azriyenni, et al., "Fuzzy Neural Network for Classification Fault in Protection System," Indonesian Journal of Electrical Engineering and Computer Science, vol/issue: 12(8), pp. 5969-5975, 2014.

[13] Barros J. and Drake J. M., "Realtime fault detection and classification in power systems using microprocessors," IEE Proceedings-Generation, Transmission and Distribution, vol/issue: 141(4), pp. 315-22, 1994.

[14] S. Narayana, et al., "Identification of Faults in HVDC System using Wavelet Analysis," International Journal of Electrical and Computer Engineering, vol/issue: 2(2), pp. 175, 2012.

[15] A. Mukherjee, et al., "Identification and Classification of Power System Faults using Ratio Analysis of Principal Component Distances," Indonesian Journal of Electrical Engineering and Computer Science, vol/issue: 12(11), pp. 7603-7612, 2014.

[16] M. Choudhury and A. Ganguly, "Transmission line fault classification using discrete wavelet transform," Energy, Power and Environment: Towards Sustainable Growth (ICEPE), 2015 International Conference on. IEEE, 2015.

[17] Mahanty R. N. and Gupta P. D., "A fuzzy logic based fault classification approach using current samples only," Electric power systems research, vol/issue: 77(5), pp. 501-7, 2007.

[18] Nayak P. K., et al., "Secured zone 3 protection during stressed condition," IEEE Transactions on Power Delivery, vol/issue: 30(1), pp. 89-96, 2015

[19] Khodaparast J. and Khederzadeh M., "Three-phase fault detection during power swing by transient monitor," IEEE Transactions on Power Systems, vol/issue: 30(5), pp. 2558-65, 2015.

[20] Sodhi R., et al., "A transient monitor to reflect the quality of synchrophasors in Power and Energy Society General Meeting," 2010 IEEE, pp. 1-6, 2010.

\section{BIOGRAPHIES OF AUTHORS}

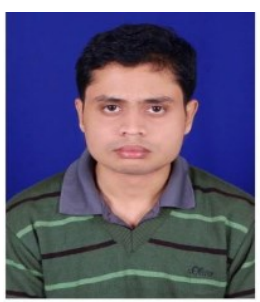

Received the B.Tech in Electrical Engineering from BPUT and M.Tech degrees from SOA University in 2011 and 2014 respectively. He is currently working towards the Ph.D degree at SOA Demmed University. His research interest are Power System Protection and Power System Transients.

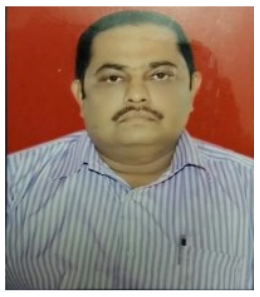

Received the B.Sc(Engg), M.E in Electrical engineering from Sambalpur University and Ph.D from KIIT University in 1990, 1997 and 2017 respectively. He is currently an associate professor in the department of electrical engineering at SOA Demmed University. His research area includes Power System Protection and Power System Transients.

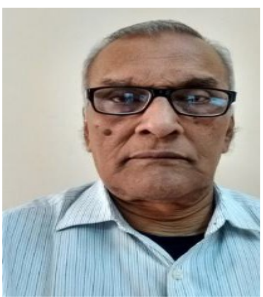

Received the B.Sc(Engg), M.Sc(Engg) and Ph.D degrees in Electrical Engineering from Sambalpur University in 1970, 1973 and 1980 respectively. He is currently a professor in the department of electrical engineering at SOA Demmed University. His research area includes Power System Protection and Power System Operation and Control. 